Article

\title{
Predicting the Risk of Ischemic Stroke among Patients with Rheumatoid Arthritis Using a Simplified RA-CHADSV Score Based on the $\mathrm{CHA}_{2} \mathrm{DS}_{2}$-VASc Score
}

\author{
Chia-Wen Hsu ${ }^{1,2,+}$, Khai-Jing Ng ${ }^{3,+}$, Ming-Chi Lu ${ }^{3,4}$ and Malcolm Koo ${ }^{5,6, *(1)}$ \\ 1 Department of Medical Research, Dalin Tzu Chi Hospital, Buddhist Tzu Chi Medical Foundation, Dalin, \\ 62247 Chiayi, Taiwan; chiawen0114@yahoo.com.tw \\ 2 School of Nursing, College of Medicine, Chang Gung University, 33302 Taoyuan City, Taiwan \\ 3 Division of Allergy, Immunology and Rheumatology, Dalin Tzu Chi Hospital, Buddhist Tzu Chi Medical \\ Foundation, Dalin, 62247 Chiayi, Taiwan; khaijingcool88@gmail.com (K.-J.N.); \\ e360187@yahoo.com.tw (M.-C.L.) \\ 4 School of Medicine, Tzu Chi University, Hualien City, 97004 Hualien, Taiwan \\ 5 Graduate Institute of Long-term Care, Tzu Chi University of Science and Technology, Hualien City, \\ 97005 Hualien, Taiwan \\ 6 Dalla Lana School of Public Health, University of Toronto, Toronto, M5T 3M7 ON, Canada \\ * Correspondence: m.koo@utoronto.ca \\ + These authors contributed equally to this work.
}

Received: 2 January 2020; Accepted: 6 February 2020; Published: 12 February 2020

\begin{abstract}
Background and Objectives: The aim of this retrospective cohort study was to develop a new score (RA-CHADSV) (rheumatoid arthritis - congestive heart failure, hypertension, age $\geq 75$ years, diabetes mellitus, stroke/transient ischemic attack/thromboembolism, and vascular disease), modified from the $\mathrm{CHA}_{2} \mathrm{DS}_{2}$-VASc score (congestive heart failure, hypertension, age $\geq 75$ years (doubled), diabetes mellitus, stroke/transient ischemic attack (doubled), vascular disease, age 65-74 years, and female), in predicting the risk of ischemic stroke in rheumatoid arthritis (RA) patients without atrial fibrillation (AF). Materials and Methods: Using the Taiwan's National Health Insurance Research Database, 592 patients with RA diagnosed between 2000 and 2002 were identified and followed until first occurrence of ischemic stroke or the last available date in the database. Incidence rate ratios (IRR) of ischemic stroke for the $\mathrm{CHA}_{2} \mathrm{DS}_{2}$-VASc score were calculated using Poisson regression models. A new prediction score RA-CHADSV was developed using multiple logistic regression analysis with bootstrap validation. Results: The area under the receiver operating characteristic curve of the newly developed RA-CHADSV score and the $\mathrm{CHA}_{2} \mathrm{DS}_{2}$-VASc score were 0.73 (95\% confidence interval (CI) $0.64-0.82)$ and 0.70 (95\% CI 0.61-0.79), respectively. The RA-CHADSV score was significantly associated with a higher ischemic stroke incidence in the patients who scored $\geq 1$ (adjusted IRR $7.39, p<0.001)$. Conclusions: A simplified RA-CHADSV score, with comparable efficiency as the $\mathrm{CHA}_{2} \mathrm{DS}_{2}$-VASc score, but easier to use clinically was developed for predicting the risk of ischemic stroke among non-AF RA patients.
\end{abstract}

Keywords: stroke; rheumatoid arthritis; atrial fibrillation; brain ischemia; risk assessment

\section{Introduction}

Rheumatoid arthritis (RA) is one of the most prevalent chronic inflammatory polyarthritis with a prevalence of $0.5-1 \%$ with female predominance in industrialized countries [1]. The risk of stroke is higher in patients with RA compared with the general population or patients with noninflammatory 
arthropathies [2-5]. Patients with RA are also at a higher risk for long-term disability after stroke [6]. Previous research has shown that the presence of autoantibodies, autoantigens, and pro-inflammatory cytokines in autoimmune diseases could accelerate the process of atherosclerosis [7,8]. Abnormal endothelial function and arterial intima-media thickening could cause the formation of atherosclerotic lesions [7], and these lesions are prone to rupture in patients with RA [8,9]. Therefore, patients with RA were associated with a higher risk of stroke $[10,11]$, which might lead to long-term disability after stroke [6] and increased mortality [12].

Several numerical tools have recently been developed for the prediction of ischemic stroke $[13,14]$. The $\mathrm{CHADS}_{2}$ score (congestive heart failure, hypertension, age $\geq 75$ years, diabetes mellitus, and stroke [doubled]) and its updated version $\mathrm{CHA}_{2} \mathrm{DS}_{2}$-VASc score (congestive heart failure, hypertension, age $\geq 75$ years (doubled), diabetes mellitus, stroke/transient ischemic attack (doubled), vascular disease, age 65-74 years, and female) are commonly used clinical prediction rules for estimating the risk of major adverse cardiovascular events (MACE) among patients with atrial fibrillation (AF) [15-18]. These scores are also widely used in the decision making of atrial fibrillation ablation and non-valvular atrial fibrillation (NVAF) to predict the risk of MACE and stroke $[19,20]$. Recently, the $\mathrm{CHA}_{2} \mathrm{DS}_{2}-\mathrm{VASc}_{\mathrm{C}}$ has been used for the evaluation of the risk of stroke and MACE in specific populations without AF [21,22], including heart failure, systemic lupus erythematosus, diabetes, hemodialysis, and RA [23-26]. We proposed that the risk of ischemic stroke might be different in patients with RA. The aim of this secondary retrospective cohort study was to develop a new and simplified score, based on the CHADS 2 and $\mathrm{CHA}_{2} \mathrm{DS}_{2}$-VASc scores, for predicting the risk of ischemic stroke in RA patients without AF.

\section{Materials and Methods}

\subsection{Data Source}

This retrospective cohort study used data from the Longitudinal Health Insurance Database 2000 (LHID 2000). The LHID 2000 contains one million randomly selected patients, excluding medical personnel, from the year 2000 Registry of Beneficiaries of the Taiwan's National Health Insurance Research Database. No statistical significant differences existed in the age, sex, or health-care costs between the LHID 2000 and all enrollees of the Taiwan's National Health Insurance (NHI) program. The NHI program is a single-payer universal health insurance plan covering the health care services for over 99\% of Taiwan's residents [27]. The study protocol was approved by the Institutional Review Board of Dalin Tzu Chi Hospital, Buddhist Tzu Chi Medical Foundation, Taiwan (No. B10004021) on 20 January 2012.

\subsection{Study Population}

In this study, patients with RA were identified from the LHID 2000 using the International Classification of Disease, 9th Revision, Clinical Modification (ICD-9-CM) code 714.0, from 1 January 2000 to 31 December 2002. We excluded patients who were diagnosed with AF or atrial flutter (ICD-9-CM codes 427.31 and 427.32 [25]) and under 20 years of age.

A total of 592 non-AF RA patients were included in the study, and 477 patients were females (80.6\%), 460 patients were $\leq 64$ year-old $(77.7 \%)$, and $33.6 \%$ had at least one comorbidities. The two most common comorbidities were hypertension $(20.8 \%)$ and diabetes mellitus (8.3\%). The mean follow-up period was 9.97 years (Table 1 ). 
Table 1. Baseline characteristics of the study participants $(\mathrm{N}=592)$.

\begin{tabular}{lcc}
\hline \multicolumn{1}{c}{ Variable } & $n$ & $\mathbf{( \% )}$ \\
\hline Age, years & & \\
\hline$\leq 64$ & 460 & $(77.7)$ \\
$65-74$ & 87 & $(14.7)$ \\
$\geq 75$ & 45 & $(7.6)$ \\
\hline Sex & & \\
\hline Female & 477 & $(80.6)$ \\
Male & 115 & $(19.4)$ \\
\hline Comorbidities (at least one condition) & 199 & $(33.6)$ \\
\hline Hypertension & 123 & $(20.8)$ \\
Diabetes mellitus & 49 & $(8.3)$ \\
Congestive heart failure & 2 & $(0.3)$ \\
Previous stroke/transient ischemic attack & 7 & $(1.2)$ \\
Vascular disease & 6 & $(1.0)$ \\
Hyperlipidemia & 27 & $(4.6)$ \\
Chronic obstructive pulmonary disease & 36 & $(6.1)$ \\
Chronic kidney disease & 6 & $(1.0)$ \\
Obesity & 1 & $(0.2)$ \\
\hline Mean follow up, years (standard deviation) & 9.97 & $(2.84)$ \\
\hline CHA 2 DS ${ }_{2}$-VASc score & & \\
\hline Mean (standard deviation) & 1.44 & $(1.05)$ \\
0-1 & 396 & $(66.9)$ \\
$\geq 2$ & 196 & $(33.1)$ \\
\hline
\end{tabular}

$\mathrm{CHA}_{2} \mathrm{DS}_{2}$-VASc: congestive heart failure, hypertension, age $\geq 75$ years (doubled), diabetes mellitus, prior stroke or transient ischemic attack (doubled), vascular disease, age 65-74 years, and female.

\subsection{Outcome Measurement and Comorbidities}

Patients were followed until first occurrence of ischemic stroke (ICD-9-CM codes 433.x1, 434 (excluding 434.x0), 435, and 436), [28,29] or the last available date in the database. The longest follow-up duration was up to 10 years. The $\mathrm{CHA}_{2} \mathrm{DS}_{2}$-VASc score was applied to evaluate the risk of ischemic stroke among RA patients without $\mathrm{AF}$.

The $\mathrm{CHADS}_{2}$ score was calculated according to the following algorithm with five variables: congestive heart failure (ICD-9-CM code 428, 1 point), hypertension (ICD-9-CM codes 401-405, 1 point), age $\geq 75$ years ( 1 point), diabetes (ICD-9-CM code 250, 1 point), and prior ischemic stroke/transient ischemic attack (ICD-9-CM codes $433-438,2$ points). The $\mathrm{CHA}_{2} \mathrm{DS}_{2}-\mathrm{VASc}$ score was calculated according to the following algorithm with 8 variables: Congestive heart failure (ICD-9-CM code 428, 1 point), hypertension (ICD-9-CM codes 401-405, 1 point), diabetes (ICD-9-CM code 250, 1 point), age $\geq$ 75 years (2 points), prior ischemic stroke/transient ischemic attack (ICD-9-CM codes 433-438, 2 points), vascular disease (ICD-9-CM codes 410.x, 411.0, 412, 420.20-420.24, 429.79, 440.0, 440.20-440.24, $440.29,440.30-440.32,440.4,443.81,443.89$, and 443.9), age 65-75 years (1 point), and female sex (1 point) [24,30,31].

In AF patients, a $\mathrm{CHADS}_{2}$ score $\geq 2$ or a $\mathrm{CHA}_{2} \mathrm{DS}_{2}$-VASc score $\geq 2$ was considered as high risk for stroke, respectively [32]. Comorbidities related to ischemic stroke, including hyperlipidemia (ICD-9-CM code 272), chronic obstructive pulmonary disease (ICD-9-CM codes 491, 492, and 496), and chronic kidney disease (ICD-9-CM codes 585, 586, 588.8, and 588.9), and obesity (ICD-9-CM code 278) were included as potential confounding variables $[24,30,31,33-36]$. 


\subsection{Statistical Analysis}

Baseline characteristics of the study participants are shown as means and standard deviations (SDs) or frequency and percentages for continuous and categorical variables, respectively. Receiver operating characteristic (ROC) curve was constructed to assess the predictive ability of the $\mathrm{CHADS}_{2}$ score and $\mathrm{CHA}_{2} \mathrm{DS}_{2}$-VASc score for ischemic stroke. The incidence rates per 10,000 person-years were calculated for ischemic stroke separately for the $\mathrm{CHA}_{2} \mathrm{DS}_{2}$-VASc score $<2$ cohort and the $\mathrm{CHA}_{2} \mathrm{DS}_{2}$-VASc score $\geq 2$ cohort. The cumulative incidence of ischemic stroke in the non-AF RA patients for the two cohorts was determined using the Kaplan-Meier method and compared with log-rank test. The incidence rates and incidence rate ratios (IRRs) of the outcome variables, stratified by follow-up periods, between the $\mathrm{CHA}_{2} \mathrm{DS}_{2}$-VASc score $0-1$ and $\geq 2$ cohorts were calculated using univariate and multiple Poisson regression models (i.e., generalized linear outcome with a Poisson log-liner link function and person-years as the offset variable), adjusting for dyslipidemia, chronic obstructive pulmonary disease, chronic kidney disease, and obesity.

Regarding the model development for the new RA-CHADSV score (congestive heart failure, hypertension, age $\geq 75$ years, diabetes mellitus, stroke/transient ischemic attack/thromboembolism, and vascular disease), we used multiple logistic regression analysis to obtain regression coefficients. The model was validated internally with a bootstrap approach using 1000 samples by resampling with replacement from the original sample with bias-corrected and accelerated confidence interval [37]. The new model of RA-CHADSV score was calculated as the following algorithm: congestive heart failure ( 1 point), hypertension ( 1 point), age $\geq 75$ years ( 1 point), diabetes mellitus ( 1 point), stroke/transient ischemic attack/thromboembolism (1 point), and vascular disease (1 point). All statistical analyses were performed using IBM SPSS Statistics for Windows, Version 24.0 (IBM Corp, Armonk, NY, USA). A two-tailed $p$ value of $<0.05$ was considered statistically significant.

\section{Results}

For the $\mathrm{CHA}_{2} \mathrm{DS}_{2}$-VASc score, 396 patients score $0-1$, and 196 patients score $2-9$. The area under the curve (AUC) of the ROC curve of $\mathrm{CHADS}_{2}$ score was 0.52 (95\% CI: 0.42-0.62, $p=0.671$ ) (Figure A1) and that of the $\mathrm{CHA}_{2} \mathrm{DS}_{2}$-VASc score was 0.70 (95\% CI: 0.61-0.79, $p<0.001$ ) (Figure A2), which showed the ability of the two scores to discriminate ischemic stroke in non-AF RA patients. Figure 1 signifies that non-AF RA patients with $\mathrm{CHA}_{2} \mathrm{DS}_{2}$-VASc score $\geq 2$ show significantly higher incidence rates of ischemic stroke compared to those with $\mathrm{CHA}_{2} \mathrm{DS}_{2}$-VASc score $<2(p<0.001)$.

Table 2 shows the incidence rates and IRRs of ischemic stroke for patients with $\mathrm{CHA}_{2} \mathrm{DS}_{2}$-VASc score $0-1$ and $\geq 2$. The incidence rates of ischemic stroke in non-AF RA patients with $\mathrm{CHA}_{2} \mathrm{DS}_{2}$-VASc score $0-1$ and $\geq 2$ were 23.81 and 146.89 per 10,000 person-years, respectively. A significantly higher incidence of ischemic stroke in patients who scored $\geq 2$ was observed (adjusted IRR 6.00, $p<0.001$ ). Table 2 also shows the incidence rates and IRRs of ischemic stroke with stratification by follow-up years. Significantly higher incidences of ischemic stroke were observed in patients with a $\mathrm{CHA}_{2} \mathrm{DS}_{2}-\mathrm{VASc}$ score $\geq 2$ compared to those with a $\mathrm{CHA}_{2} \mathrm{DS}_{2}$-VASc score of 0 or 1 . The adjusted IRR was $5.38(p<0.001)$ and $5.91(p<0.001)$ for a follow-up of 5 and 10 years, respectively. 


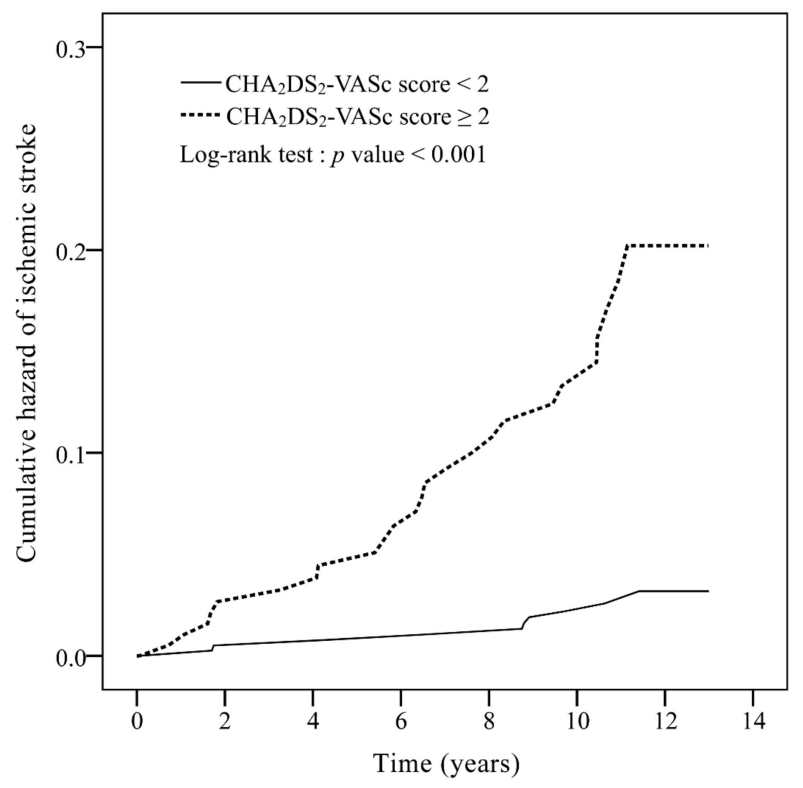

Figure 1. Cumulative incidence curves of ischemic stroke for rheumatoid arthritis patients without atrial fibrillation, with a $\mathrm{CHA}_{2} \mathrm{DS}_{2}$-VASc score $0-1$ and $\mathrm{CHA}_{2} \mathrm{DS}_{2}$-VASc score $\geq 2 . \mathrm{CHA}_{2} \mathrm{DS}_{2}$-VASc: congestive heart failure, hypertension, age $\geq 75$ years (doubled), diabetes mellitus, prior stroke or transient ischemic attack (doubled), vascular disease, age 65-74 years, and female.

Table 2. Incidence rates and incidence rate ratio of ischemic stroke for patients with rheumatoid arthritis according to $\mathrm{CHA}_{2} \mathrm{DS}_{2}$-VASc score $\geq 2$, with stratification by follow up years $(\mathrm{N}=592)$.

\begin{tabular}{|c|c|c|c|c|c|c|}
\hline $\begin{array}{c}\mathrm{CHA}_{2} \mathrm{DS}_{2}-\mathrm{VASc} \\
\text { Score }\end{array}$ & Follow Up & Events & Person-Years & $\begin{array}{c}\text { IR } \\
\text { (per 10,000 } \\
\text { Person-Years) }\end{array}$ & $\begin{array}{c}\text { IRR }(95 \% \text { CI) } \\
p \text { Value }\end{array}$ & $\begin{array}{c}\text { Adjusted IRR * } \\
(95 \% \text { CI }) \\
p \text { Value }\end{array}$ \\
\hline Continuous score & Overall & 35 & 5902 & 59.30 & $\begin{array}{c}1.90(1.52-2.37) \\
<0.001\end{array}$ & $\begin{array}{c}1.75(1.39-2.19) \\
<0.001\end{array}$ \\
\hline \multicolumn{7}{|c|}{ Dichotomized score } \\
\hline $0-1$ & Overall & 10 & 4200 & 23.81 & 1 & 1 \\
\hline$\geq 2$ & Overall & 25 & 1702 & 146.89 & $\begin{array}{c}6.10(2.93-12.69) \\
<0.001\end{array}$ & $\begin{array}{c}6.00(2.88-12.52) \\
<0.001\end{array}$ \\
\hline Continuous score & 5 -year & 11 & 2837 & 38.77 & $\begin{array}{c}1.68(1.11-2.54) \\
0.013\end{array}$ & $\begin{array}{c}1.48(0.98-2.23) \\
0.062\end{array}$ \\
\hline \multicolumn{7}{|c|}{ Dichotomized score } \\
\hline $0-1$ & 5-year & 3 & 1940 & 15.46 & 1 & 1 \\
\hline$\geq 2$ & 5-year & 8 & 897 & 89.19 & $\begin{array}{c}5.77(1.53-21.75) \\
0.010\end{array}$ & $\begin{array}{c}5.38(1.42-20.36) \\
0.013\end{array}$ \\
\hline Continuous score & 10-year & 28 & 5306 & 52.77 & $\begin{array}{c}1.87(1.46-2.39) \\
<0.001\end{array}$ & $\begin{array}{c}1.70(1.32-2.19) \\
<0.001\end{array}$ \\
\hline \multicolumn{7}{|c|}{ Dichotomized score } \\
\hline $0-1$ & 10-year & 8 & 3738 & 21.40 & 1 & 1 \\
\hline$\geq 2$ & 10-year & 20 & 1568 & 127.55 & $\begin{aligned} 5.96 & (2.62-13.53) \\
& <0.001\end{aligned}$ & $\begin{array}{c}5.91(2.60-13.45) \\
<0.001\end{array}$ \\
\hline
\end{tabular}

$\mathrm{CI}$ : confidence interval; IR: incidence rate; IRR: incidence rate ratio; $\mathrm{CHA}_{2} \mathrm{DS}_{2}$-VASc: congestive heart failure, hypertension, age $\geq 75$ years (doubled), diabetes mellitus, stroke/transient ischemic attack (doubled), vascular disease, age 65-74 years, and female. * Adjusted for the patient dyslipidemia, chronic obstructive pulmonary disease, chronic kidney disease, and obesity.

A new and simplified score for improving the prediction of ischemic stroke risk in patients with non-AF RA based on the $\mathrm{CHA}_{2} \mathrm{DS}_{2}$-VASc score was developed and shown in Table 3. Based on the results of the logistic model obtained while simultaneously considering clinical convenience, variables with a logistic regression coefficient near zero were omitted from the final model (age 65-74 years and 
female). In addition, the regression coefficients were round to one significant figure for convenience. For congestive heart failure, we compared the AUC obtained based on a regression coefficient of 1 and 2 , and found no differences between the two. Therefore, the variable congestive heart failure was given a score of 1 in the final model. Correspondingly, our new proposed score RA-CHADSV is named based on the acronym of the items in it: congestive heart failure (1 point), hypertension (1 point), age $\geq 75$ years (1 point), diabetes mellitus (1 point), stroke/transient ischemic attack/thromboembolism (1 point), and vascular disease (1 point). A RA-CHADSV score $\geq 1$ suggested a higher risk of ischemic stroke [26].

Table 3. Multiple logistic regression model for the development of the retrospective cohort study was to develop a new score (RA-CHADSV) score.

\begin{tabular}{cccc}
\hline Variable & Adjusted $\beta$ & Standard Error & 95\% CI \\
\hline Congestive heart failure & 1.60 & 17.94 & $-19.12-42.26$ \\
Hypertension & 1.32 & 0.41 & $0.49-2.23$ \\
Age $\geq$ 75 years & 0.57 & 1.17 & $-1.04-1.70$ \\
Diabetes mellitus & 1.31 & 0.52 & $0.06-2.45$ \\
Stroke/transient ischemic attack/thromboembolism & 0.50 & 9.72 & $-19.65-2.89$ \\
Vascular disease & 1.35 & 9.60 & $-19.71-4.51$ \\
Age 65-74 years & -0.11 & 1.04 & $-1.15-0.59$ \\
Female & 0.08 & 0.85 & $-0.93-1.47$ \\
\hline
\end{tabular}

$\beta$ : logistic regression coefficient; CI: confidence interval. Adjusted $\beta$ were obtained with bootstrap methods based on 1000 replications.

The AUC of ROC curve of the new RA-CHADSV score was 0.73 (95\% CI: $0.64-0.82, p<0.001$ ) (Figure A3). Patients with RA-CHADSV score $\geq 1$ showed a significantly higher incidence rate of ischemic stroke compared to those who scored $0(p<0.001)$ (Figure 2). Table 4 showed that with every one unit of increment in the RA-CHADSV score, the risk of ischemic stroke increased 2.49 times $(p<0.001)$. In addition, a significantly higher ischemic stroke incidence in the patients who scored $\geq 1$, compared with those who scored 0 , was observed with an adjusted IRR of $7.39(p<0.001)$.

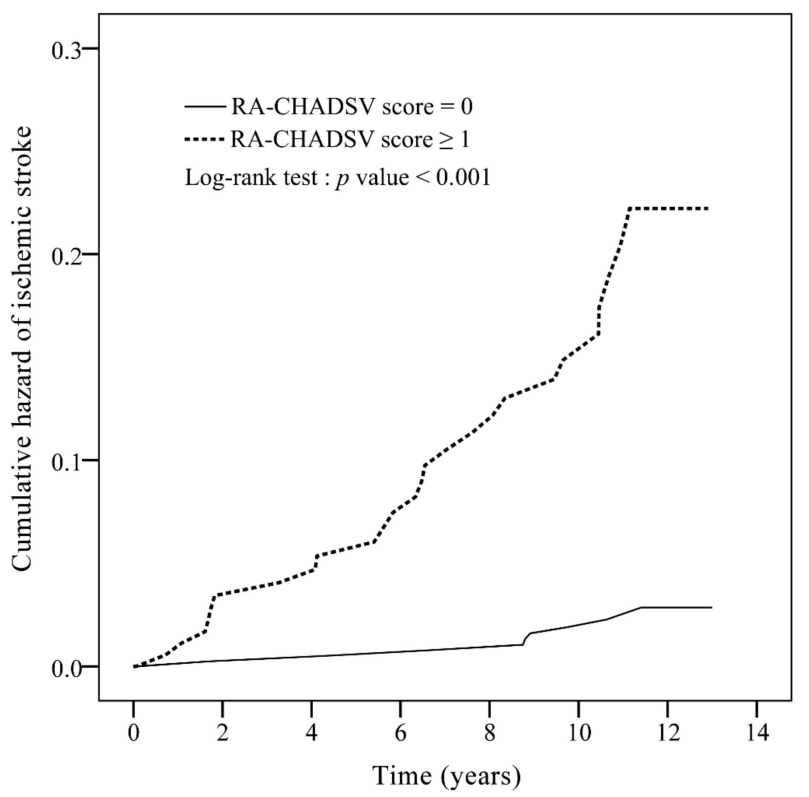

Figure 2. Cumulative incidence curves of ischemic stroke for rheumatoid arthritis patients without atrial fibrillation, with a RA-CHADSV score 0 and RA-CHADSV score $\geq 1$. RA-CHADSV: rheumatoid arthritis - congestive heart failure, hypertension, age $\geq 75$ years, diabetes mellitus, stroke/transient ischemic attack/thromboembolism, and vascular disease. 
Table 4. Incidence rates and incidence rate ratio of ischemic stroke for patients with rheumatoid arthritis according to the new RA-CHADSV score $(\mathrm{N}=592)$.

\begin{tabular}{cccccc}
\hline RA-CHADSV Score & Events & Person-Years & $\begin{array}{c}\text { IR (10,000 } \\
\text { Person-Years) }\end{array}$ & $\begin{array}{c}\text { IRR (95\% CI) } \\
\boldsymbol{p} \text { Value }\end{array}$ & $\begin{array}{c}\text { Adjusted IRR * } \\
\mathbf{9 5 \%} \text { CI) } \\
\boldsymbol{p} \text { Value }\end{array}$ \\
\hline Continuous score & 35 & 5902 & 59.30 & $\begin{array}{c}2.82(2.10-3.80) \\
<0.001\end{array}$ & $\begin{array}{c}2.49(1.78-3.49) \\
<0.001\end{array}$ \\
\hline 0 & 9 & 4318 & 27.79 & 1 & 1 \\
\hline$\geq 1$ & 26 & 1585 & 145.11 & $\begin{array}{c}7.70(3.61-16.44) \\
<0.001\end{array}$ & $\begin{array}{c}7.39(3.42-15.74) \\
<0.001\end{array}$ \\
\hline
\end{tabular}

CI: confidence interval; IR: incidence rate; IRR: incidence rate ratio; RA-CHADSV: rheumatoid arthritis - congestive heart failure, hypertension, age $\geq 75$ years, diabetes mellitus, stroke/transient ischemic attack/thromboembolism, and vascular disease. *Adjusted for dyslipidemia, chronic obstructive pulmonary disease, chronic kidney disease, and obesity.

RA-CHADSV score was calculated according to: congestive heart failure (1 point), hypertension (1 point), age $\geq 75$ (1 point), diabetes mellitus (1 point), stroke/transient ischemic attack/thromboembolism (1 point), and vascular disease (1 point).

\section{Discussion}

This retrospective cohort study has three main findings. First, the $\mathrm{CHA}_{2} \mathrm{DS}_{2}$-VASc score was able to moderately predict the risk of ischemic stroke in non-AF RA patients, with a score of $\geq 2$ possessed a higher risk of ischemic stroke than patients with a score of $0-1$. Second, the $\mathrm{CHADS}_{2}$ score inadequately predicted the risk of ischemic stroke in non-AF RA patients. Third, our newly developed RA-CHADSV score (consisted of six variables with equal weights of one: Congestive heart failure, hypertension, age $\geq 75$ years, diabetes mellitus, stroke/transient ischemic attack/thromboembolism, and vascular disease) showed similar performance compared with the original $\mathrm{CHA}_{2} \mathrm{DS}_{2}$-VASc score in predicting the risk of ischemic stroke in non-AF RA patients. Our study results support the clinical utility of $\mathrm{CHA}_{2} \mathrm{DS}_{2}$-VASc score in prediction of the MACE in non-AF RA patients [26]. In addition, we showed that the new RA-CHADSV score was able to predict the risk of ischemic stroke in patients with non-AF RA.

Our results showed that non-AF RA patients possessed a significantly higher risk of ischemic stroke with a follow-up of ten years. The most common comorbidity in our patients was hypertension, which accounted for $33.6 \%$ of patients. This result was similar to a previous study where RA patients tended to develop more than one comorbidity within 5 years after diagnosis of RA, with the most common comorbidity was found to be hypertension [38].

The $\mathrm{CHA}_{2} \mathrm{DS}_{2}$-VASc score have been used extensively to predict the risk of ischemic stroke in certain individuals $[17,20,23,25]$. Previous research revealed that patients with RA were at a higher risk for cardiovascular disease compared to patients with other immune-mediated diseases $[39,40]$. Our finding that non-AF RA patients with a $\mathrm{CHA}_{2} \mathrm{DS}_{2}$-VASc score of $\geq 2$ had a higher risk of ischemic stroke is similar to the case of systemic lupus erythematosus patients without AF [25]. Previous studies have also demonstrated an increased risk of ischemic stroke 10 or more years after RA diagnosis $[3,4,41]$. This result was also observed in our study, especially in patients with a higher $\mathrm{CHA}_{2} \mathrm{DS}_{2}$-VASc score $(\geq 2)$. However, not all the parameters in the $\mathrm{CHA}_{2} \mathrm{DS}_{2}$-VASc score can be applicable for patients with RA, hence we developed a new score for non-AF RA patients based on multiple logistic regression analysis with bootstrapping internal validation. The ROC curve of RA-CHADSV and the $\mathrm{CHA}_{2} \mathrm{DS}_{2}$-VASc score was 0.73 and 0.70 , respectively. Despite the simplicity (only six variables of equal weights) of our new model, the performance was comparable with the original $\mathrm{CHA}_{2} \mathrm{DS}_{2}$-VASc score in predicting ischemic stroke risk among non-AF RA patients.

This study has a few limitations that should be noted. Patient's physical activity, lifestyle factors, and laboratory data were not available in the LHID, and therefore could not be adjusted in the statistical 
models. The model for the new RA-CHADV score was validated internally using bootstrap method, which should be externally validated in future studies.

\section{Conclusions}

Findings from this retrospective cohort study showed that $\mathrm{CHA}_{2} \mathrm{DS}_{2}$-VASc score was able to moderately predict the risk of ischemic stroke in non-AF RA patients. Furthermore, a new RA-CHADSV score was developed in this study, which was based on six variables, including congestive heart failure, hypertension, age $\geq 75$ years, diabetes mellitus, stroke/transient ischemic attack/thromboembolism, and vascular disease. This simple tool could be used to identify non-AF RA patients with an increased risk of ischemic stroke, and to help physicians in the management of these patients.

Author Contributions: Conceptualization, K.-J.N. and M.-C.L.; methodology, M.-C.L.; formal analysis, C.-W.H.; writing—original draft preparation, K.-J.N., C.-W.H., and M.-C.L.; writing—review and editing, M.-C.L. and M.K. All authors have read and agree to the published version of the manuscript.

Funding: This research received no external funding.

Acknowledgments: This study is based in part on data from the National Health Insurance Research Database provided by the National Health Insurance Administration, Ministry of Health and Welfare and managed by the National Health Research Institutes, Taiwan. The interpretation and conclusions contained herein do not represent those of the National Health Insurance Administration, Ministry of Health and Welfare or the National Health Research Institutes, Taiwan.

Conflicts of Interest: The authors declare there are no conflicts of interest.

\section{Appendix A}

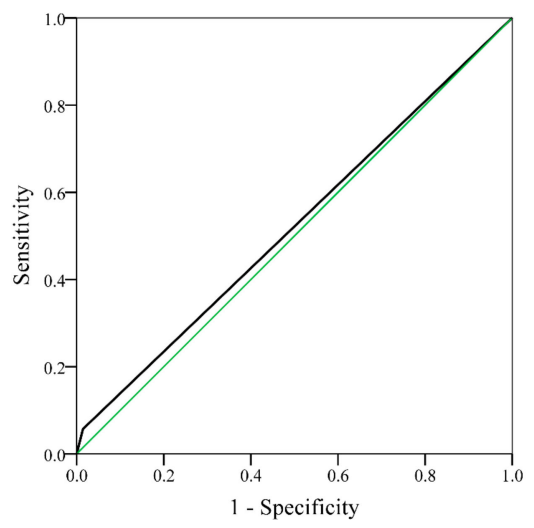

Figure A1. Receiver operating characteristic curve of ischemic stroke for rheumatoid arthritis patients without atrial fibrillation, with a CHADS 2 score $0-1$ and $\mathrm{CHADS}_{2}$ score $\geq 2$ (area under the curve $=0.52$, $95 \%$ CI $0.42-0.62, p=0.671$ ). $\mathrm{CHADS}_{2}$ : congestive heart failure, hypertension, age $\geq 75$ years, diabetes mellitus, and stroke [doubled]); CI: confidence interval. 


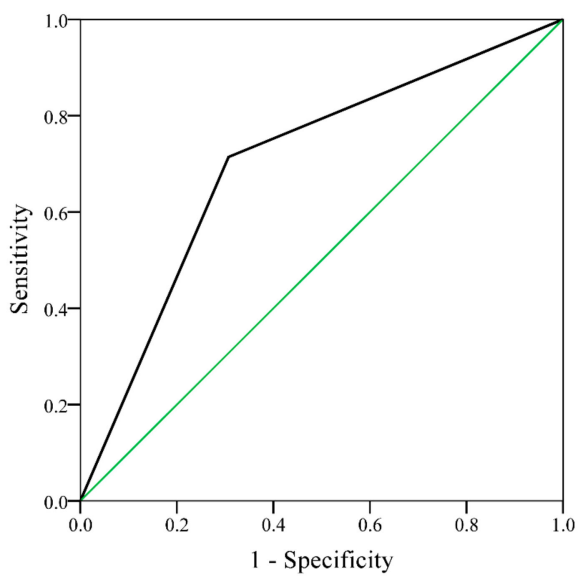

Figure A2. Receiver operating characteristic curve of ischemic stroke for rheumatoid arthritis patients without atrial fibrillation, with a $\mathrm{CHA}_{2} \mathrm{DS}_{2}$ score $0-1$ and $\mathrm{CHA}_{2} \mathrm{DS}_{2}$ score $\geq 2$ (area under the curve = $0.70,95 \% \mathrm{CI} 0.61-0.79, p<0.001) . \mathrm{CHA}_{2} \mathrm{DS}_{2}$-VASc: congestive heart failure, hypertension, age $\geq 75$ years (doubled), diabetes mellitus, stroke/transient ischemic attack (doubled), vascular disease, age 65-74 years, and female; CI: confidence interval.

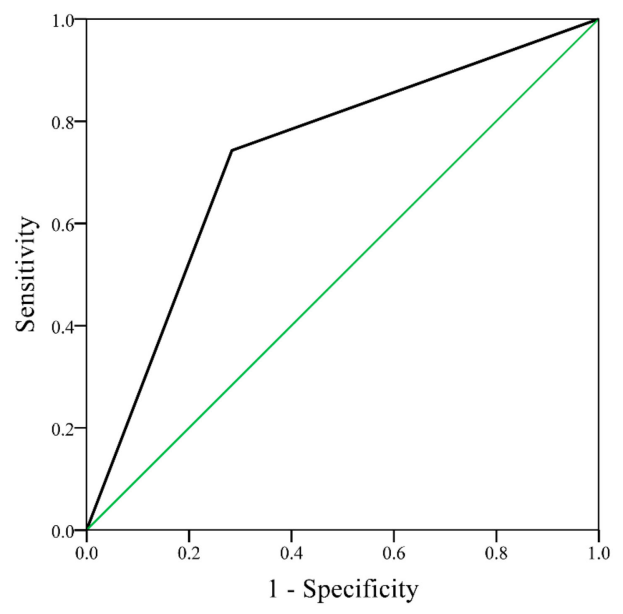

Figure A3. Receiver operating characteristic curve of ischemic stroke for rheumatoid arthritis patients without atrial fibrillation, with a RA-CHADSV score 0 and RA-CHADSV score $\geq 1$ (area under the curve $=0.73,95 \%$ CI $0.64-0.82, p<0.001)$. RA-CHADSV: congestive heart failure, hypertension, age $\geq 75$ years, diabetes mellitus, stroke/transient ischemic attack/thromboembolism, and vascular disease; CI: confidence interval.

\section{References}

1. Scott, D.L.; Wolfe, F.; Huizinga, T.W. Rheumatoid arthritis. Lancet 2010, 376, 1094-1108. [CrossRef]

2. Avina-Zubieta, J.A.; Thomas, J.; Sadatsafavi, M.; Lehman, A.J.; Lacaille, D. Risk of incident cardiovascular events in patients with rheumatoid arthritis: A meta-analysis of observational studies. Ann. Rheum. Dis. 2012, 71, 1524-1529. [CrossRef] [PubMed]

3. Tam, H.W.; Chen, C.M.; Leong, P.Y.; Chen, C.H.; Li, Y.C.; Wang, Y.H.; Lin, L.C.; Chiou, J.Y.; Wei, J.C. Methotrexate might reduce ischemic stroke in patients with rheumatoid arthritis: A population-based retrospective cohort study. Int. J. Rheum. Dis. 2018, 21, 1591-1599. [CrossRef] [PubMed]

4. Lindhardsen, J.; Ahlehoff, O.; Gislason, G.H.; Madsen, O.R.; Olesen, J.B.; Svendsen, J.H.; Torp-Pedersen, C.; Hansen, P.R. Risk of atrial fibrillation and stroke in rheumatoid arthritis: Danish nationwide cohort study. BMJ 2012, 344, e1257. [CrossRef] [PubMed]

5. Wiseman, S.J.; Ralston, S.H.; Wardlaw, J.M. Cerebrovascular disease in rheumatic diseases: A systematic review and meta-analysis. Stroke 2016, 47, 943-950. [CrossRef] [PubMed] 
6. Nguyen-Oghalai, T.U.; Wu, H.; McNearney, T.A.; Granger, C.V.; Ottenbacher, K.J. Functional outcome after stroke in patients with rheumatoid arthritis and systemic lupus erythematosus. Arthritis Rheum. 2008, 59, 984-988. [CrossRef]

7. Zinger, H.; Sherer, Y.; Shoenfeld, Y. Atherosclerosis in autoimmune rheumatic diseases-mechanisms and clinical findings. Clin. Rev. Allergy Immunol. 2009, 37, 20-28. [CrossRef]

8. Sherer, Y.; Shoenfeld, Y. Mechanisms of disease: Atherosclerosis in autoimmune diseases. Nat. Clin. Pract. Rheumatol. 2006, 2, 99-106. [CrossRef]

9. Skeoch, S.; Bruce, I.N. Atherosclerosis in rheumatoid arthritis: Is it all about inflammation? Nat. Rev. Rheumatol. 2015, 11, 390-400. [CrossRef]

10. Tiosano, S.; Yavne, Y.; Gendelman, O.; Watad, A.; Comaneshter, D.; Shoenfeld, Y.; Cohen, A.D.; Amital, D. Stroke among rheumatoid arthritis patients: does age matter? A real-life study. Neuroepidemiology 2017, 49, 99-105. [CrossRef]

11. Masuda, H.; Miyazaki, T.; Shimada, K.; Tamura, N.; Matsudaira, R.; Yoshihara, T.; Ohsaka, H.; Sai, E.; Matsumori, R.; Fukao, K.; et al. Disease duration and severity impacts on long-term cardiovascular events in Japanese patients with rheumatoid arthritis. J. Cardiol. 2014, 64, 366-370. [CrossRef] [PubMed]

12. Dadonienè, J.; Stropuvienè, S.; Stukas, R.; Venalis, A.; Sokka-Isler, T. Predictors of mortality in patients with rheumatoid arthritis in Lithuania: Data from a cohort study over 10 years. Medicina Kaunas 2015, 51, 25-31. [CrossRef] [PubMed]

13. Jagadish, P.S.; Kabra, R. Stroke risk in atrial fibrillation: Beyond the $\mathrm{CHA}_{2} \mathrm{DS}_{2}$-VASc score. Curr. Cardiol. Rep. 2019, 21, 95. [CrossRef] [PubMed]

14. Polanczyk, A.; Podgorski, M.; Wozniak, T.; Stefanczyk, L.; Strzelecki, M. Computational fluid dynamics as an engineering tool for the reconstruction of hemodynamics after carotid artery stenosis operation: A case study. Medicina Kaunas 2018, 54, 42. [CrossRef]

15. Zhu, W.G.; Xiong, Q.M.; Hong, K. Meta-analysis of CHADS2 versus CHA2DS2-VASc for predicting stroke and thromboembolism in atrial fibrillation patients independent of anticoagulation. Tex. Heart Inst. J. 2015, 42, 6-15. [CrossRef]

16. Lin, L.Y.; Lee, C.H.; Yu, C.C.; Tsai, C.T.; Lai, L.P.; Hwang, J.J.; Chen, P.C.; Lin, J.L. Risk factors and incidence of ischemic stroke in Taiwanese with nonvalvular atrial fibrillation-a nation wide database analysis. Atherosclerosis 2011, 217, 292-295. [CrossRef]

17. Chao, T.F.; Liu, C.J.; Tuan, T.C.; Chen, S.J.; Wang, K.L.; Lin, Y.J.; Chang, S.L.; Lo, L.W.; Hu, Y.F.; Chen, T.J.; et al. Comparisons of CHADS2 and CHA2DS2-VASc scores for stroke risk stratification in atrial fibrillation: Which scoring system should be used for Asians? Heart Rhythm 2016, 13, 46-53. [CrossRef]

18. Yang, Y.; Zhang, Z.; Ng, C.Y.; Li, G.; Liu, T. Meta-analysis of CHADS2 score in predicting atrial fibrillation. Am. J. Cardiol. 2015, 116, 554-562. [CrossRef]

19. Sugioka, K.; Fujita, S.; Iwata, S.; Ito, A.; Matsumura, Y.; Hanatani, A.; Doi, A.; Takagi, M.; Naruko, T.; Ueda, M.; et al. Relationship between CHADS2 score and complex aortic plaques by transesophageal echocardiography in patients with nonvalvular atrial fibrillation. Ultrasound Med. Biol. 2014, 40, 2358-2364. [CrossRef]

20. Senoo, K.; Lane, D.A.; Lip, G.Y. Stroke risk reduction with oral anticoagulation using CHA2DS2-VASc in a Japanese AF population: A modeling analysis. Int. J. Cardiol. 2015, 181, 247-254. [CrossRef]

21. Chen, Y.L.; Cheng, C.L.; Huang, J.L.; Yang, N.I.; Chang, H.C.; Chang, K.C.; Sung, S.H.; Shyu, K.G.; Wang, C.C.; Yin, W.H.; et al. Mortality prediction using CHADS2/CHA2DS2-VASc/R2CHADS2 scores in systolic heart failure patients with or without atrial fibrillation. Medicine Baltimore 2017, 96, e8338. [CrossRef] [PubMed]

22. Ntaios, G.; Lip, G.Y.; Makaritsis, K.; Papavasileiou, V.; Vemmou, A.; Koroboki, E.; Savvari, P.; Manios, E.; Milionis, H.; Vemmos, K. $\mathrm{CHADS}_{2}, \mathrm{CHA}_{2} \mathrm{~S}_{2} \mathrm{DS}_{2}$-VASc, and long-term stroke outcome in patients without atrial fibrillation. Neurology 2013, 80, 1009-1017. [CrossRef] [PubMed]

23. Melgaard, L.; Gorst-Rasmussen, A.; Lane, D.A.; Rasmussen, L.H.; Larsen, T.B.; Lip, G.Y. Assessment of the CHA2DS2-VASc score in predicting ischemic stroke, thromboembolism, and death in patients with heart failure with and without atrial fibrillation. JAMA 2015, 314, 1030-1038. [CrossRef] [PubMed]

24. Yang, H.; Chen, Y.H.; Hsieh, T.F.; Chuang, S.Y.; Wu, M.J. Prediction of mortality in incident hemodialysis patients: a validation and comparison of CHADS2, CHA2DS2, and CCI scores. PLoS ONE 2016, 11, e0154627. [CrossRef]

25. Hu, W.S.; Lin, C.L. CHA2DS2-VASc score for prediction of ischemic stroke in patients with systemic lupus erythematosus without atrial fibrillation. Lupus 2018, 27, 1240-1246. [CrossRef] 
26. Cioffi, G.; Viapiana, O.; Orsolini, G.; Idolazzi, L.; Fracassi, E.; Ognibeni, F.; Dalbeni, A.; Gatti, D.; Carletto, A.; Fassio, A.; et al. Usefulness of CHA2 DS2 -VASc score to predict mortality and hospitalization in patients with inflammatory arthritis. Int. J. Rheum. Dis. 2020, 23, 106-115. [CrossRef]

27. National Health Insurance Administration. Available online: https://ws.nhi.gov.tw/001/Upload/\%20293/ RelFile/Ebook/English.pdf (accessed on 28 January 2020).

28. Cozzolino, F.; Abraha, I.; Orso, M.; Mengoni, A.; Cerasa, M.F.; Eusebi, P.; Ambrosio, G.; Montedori, A. Protocol for validating cardiovascular and cerebrovascular ICD-9-CM codes in healthcare administrative databases: The umbria data value project. BMJ Open 2017, 7, e013785. [CrossRef]

29. Chen, Y.R.; Hsieh, F.I.; Lien, L.M.; Hu, C.J.; Jeng, J.S.; Peng, G.S.; Tang, S.C.; Chi, N.F.; Sung, Y.F.; Chiou, H.Y. Rheumatoid arthritis significantly increased recurrence risk after ischemic stroke/transient ischemic attack. J. Neurol. 2018, 265, 1810-1818. [CrossRef]

30. Chua, S.K.; Shyu, K.G.; Lu, M.J.; Hung, H.F.; Cheng, J.J.; Chiu, C.Z.; Lin, C.H.; Chao, H.H.; Lo, H.M. Renal dysfunction and the risk of postoperative atrial fibrillation after cardiac surgery: Role beyond the CHA2DS2-VASc score. Europace 2015, 17, 1363-1370. [CrossRef]

31. Hu, W.S.; Lin, C.L. Postoperative ischemic stroke and death prediction with CHA2DS2-VASc score in patients having coronary artery bypass grafting surgery: a nationwide cohort study. Int. J. Cardiol. 2017, 241, 120-123. [CrossRef]

32. Chiang, C.E.; Wu, T.J.; Ueng, K.C.; Chao, T.F.; Chang, K.C.; Wang, C.C.; Lin, Y.J.; Yin, W.H.; Kuo, J.Y.; Lin, W.S.; et al. 2016 Guidelines of the Taiwan Heart Rhythm Society and the Taiwan Society of Cardiology for the management of atrial fibrillation. J. Formos. Med. Assoc. 2016, 115, 893-952. [CrossRef] [PubMed]

33. Yin, L.; Lensmar, C.; Ingelsson, E.; Bäck, M. Differential association of chronic obstructive pulmonary disease with myocardialinfarction and ischemic stroke in a nation-wide cohort. Int. J. Cardiol. 2014, 173, 601-603. [CrossRef] [PubMed]

34. El Husseini, N.; Kaskar, O.; Goldstein, L.B. Chronic kidney disease and stroke. Adv. Chronic Kidney Dis. 2014, 21, 500-508. [CrossRef] [PubMed]

35. Van Rooy, M.J.; Pretorius, E. Obesity, hypertension and hypercholesterolemia as risk factors for atherosclerosis leading to ischemic events. Curr. Med. Chem. 2014, 21, 2121-2129. [CrossRef]

36. Tziomalos, K.; Athyros, V.G.; Karagiannis, A.; Mikhailidis, D.P. Dyslipidemia as a risk factor for ischemic stroke. Curr. Top. Med. Chem. 2009, 9, 1291-1297. [CrossRef]

37. Steyerberg, E.W.; Harrell, F.E., Jr.; Borsboom, G.J.; Eijkemans, M.J.; Vergouwe, Y.; Habbema, J.D. Internal validation of predictive models: Efficiency of some procedures for logistic regression analysis. J. Clin. Epidemiol. 2001, 54, 774-781. [CrossRef]

38. Innala, L.; Sjoberg, C.; Moller, B.; Ljung, L.; Smedby, T.; Sodergren, A.; Magnusson, S.; Rantapaa-Dahlqvist, S.; Wallberg-Jonsson, S. Co-morbidity in patients with early rheumatoid arthritis - inflammation matters. Arthritis Res. Ther. 2016, 18, 33. [CrossRef]

39. Baena-Diez, J.M.; Garcia-Gil, M.; Comas-Cufi, M.; Ramos, R.; Prieto-Alhambra, D.; Salvador-Gonzalez, B.; Elosua, R.; Degano, I.R.; Penafiel, J.; Grau, M. Association between chronic immune-mediated inflammatory diseases and cardiovascular risk. Heart 2018, 104, 119-126. [CrossRef]

40. Zha, A.M.; Di Napoli, M.; Behrouz, R. Prevention of stroke in rheumatoid arthritis. Curr. Neurol. Neurosci. Rep. 2015, 15, 77. [CrossRef]

41. Holmqvist, M.; Gransmark, E.; Mantel, A.; Alfredsson, L.; Jacobsson, L.T.; Wallberg-Jonsson, S.; Askling, J. Occurrence and relative risk of stroke in incident and prevalent contemporary rheumatoid arthritis. Ann. Rheum. Dis. 2013, 72, 541-546. [CrossRef]

(C) 2020 by the authors. Licensee MDPI, Basel, Switzerland. This article is an open access article distributed under the terms and conditions of the Creative Commons Attribution (CC BY) license (http://creativecommons.org/licenses/by/4.0/). 